\title{
Development of a system to increase the legal metrological control of measuring instruments in Brazil
}

\author{
A. Soratto*, O. Pohlmann Filho, M.R. de Paiva, R.B. Giordani, and C. Bringhenti
}

National Institute of Metrology, Technology and Quality (INMETRO), General-Coordination of the Brazilian Network of Legal Metrology and Quality (Cored), Rio de Janeiro, Brazil

Received: 26 February 2014 / Accepted: 10 June 2014

\begin{abstract}
This article presents the development of a system used by the Brazilian Network of Legal Metrology and Quality - INMETRO and its delegated public bodies to increase the coverage of mandatory periodic verification on measuring instruments in Brazil, especially non automatic weighing instruments. Based on a governmental database of active establishments that allowed the choice of an specific economic activity, the system provides a list of establishments where measuring instruments are used to commercial transitions and, therefore, subject to periodic mandatory verification. As a result, the use of system increased the number of measuring instruments controlled in Brazil, revealed areas for improvement and provided references to set goals.
\end{abstract}

Keywords: Legal metrology, mandatory periodic verification, measuring instruments

\section{Introduction}

The importance of legal metrology for the social and economic stability and development of a nation is undeniable $[1,2]$. Thus, it is of utmost importance that metrological control takes place in its various areas and in all regions of the country, so the confidence of measurements and their positive effects can reach the entire population.

However, for countries with large territorial area it is particularly challenging that mandatory periodic verification of measuring instruments can reach the most diverse types of establishments in different business areas.

In Brazil, the National Institute of Metrology, Quality and Technology - INMETRO - is responsible for legal metrological control regulation and delegates, under INMETRO supervison, the execution of field activities to a weighting and measuring delegated public bodies, in each state of Brazil, known as Brazilian Network of Legal Metrology and Quality - RBMLQ - consisting of 26 institutes. Their responsibility, among many others, is to carry out mandatory periodic verification of measuring instruments (Fig. 1).

A lot has been done for this metrological verification process as far as equipment, training and planning are concerned.

However, how ensure that the mandatory periodic verification of measuring instruments under legal control has achieved all establishments in the country?

One way to answer this question can be given by analyzing the universe of establishments where regulated mea-

\footnotetext{
* Correspondence: ansoratto@imetro.sc.gov.br
}

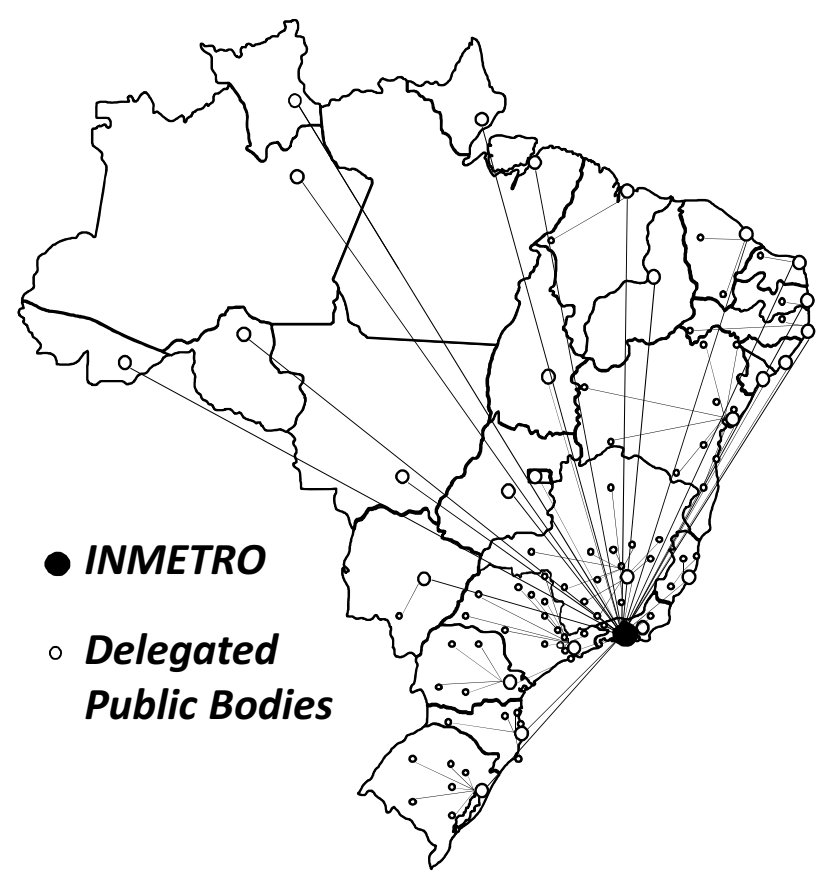

Fig. 1. INMETRO and the Brazilian network of legal metrology and quality - RBMLQ.

suring instruments can be found versus the subset of this universe in which the measuring instruments are actually periodically verified. Therefore, it is possible to find out if the coverage of periodic metrological verification is satisfactory in several different consumer business areas. 
In order to support RBMLQ regarding the coverage of their services, INMETRO, through the General Coordination of RBMLQ - CORED - developed a system called Monitoring System of Coverage - SIMCS. This system, via inputs from other sources, stores information about active establishments throughout Brazil and allows investigating the coverage of mandatory periodic verification of each RBMLQ institute in specific sectors of trade, industry, and services [3].

This article shows how SIMCS has been developed and how it is supporting the RBMLQ in the planning and expansion of metrological coverage in Brazil.

\section{The need of developing a system to support the planning and execution of mandatory periodic verification in Brazil}

Many researchers and studies stress the importance of efficiency, efficacy and effectiveness in Brazilian public service $[4,5]$.

Social and economic impacts justify the need to develop of an innovative tool to support the planning and execution of mandatory periodic verification, in order to increase the efficiency, efficacy and effectiveness of these services in Brazil.

In 2009, INMETRO took the first steps in order to identify indicators to assess the coverage of services carried out by RBMLQ [6] and, consequently, to overcome some difficulties regarding the planning and execution of mandatory periodic verification of measuring instruments in Brazil $[3,7,8]$.

Above mentioned difficulties was due to the fact that the universe of establishments and measuring instruments subject to mandatory metrological verification in Brazil was not known by INMETRO and RBMLQ and therefore the planning of this service was based only on the number of establishments visited in previous periods. Without being able to estimate the number of establishments to be visited, it was not possible to know the service coverage of metrological verification.

The initial way of RBMLQ to look for establishments not yet visited was limited to go street by street, which consumed much time and resources with questionable efficacy, since it depended exclusively on the proactivity of the field inspectors.

As a result, many measuring instruments were not being verified at appropriate intervals, making room for fraud and unfair competition in the market, as well as in healthcare area, leading to misdiagnosis, endangering the safety and even the lives of Brazilian citizens $[3,7,8]$.

\section{The development of the SIMCS}

In 2010, as a result of meetings of the RBMLQ working group involving experts in legal metrology and information technology the Monitoring System of Coverage SIMCS - was developed [3].
SIMCS development was planned considering three major steps:

Step 1 - accessing data regarding establishments that are currently operating in the country;

Step 2 - selecting economic activities of interest;

Step 3 - developing the computer architecture of SIMCS.

Step 1 - Accessing data regarding establishments which are currently operating in the country: The search focused on identifying an information basis that would provide the following prerequisites: nationwide coverage, regular updating, access without charges to INMETRO, and provide other relevant information such as name of the establishment, complete address, the national code of the establishment - CNPJ as well as the national classification number of economic activity - CNAE from the largest possible number of active establishments.

After discussions and meetings with representatives of various entities with databases of establishments in Brazil, the Annual Social Information (RAIS) of the Ministry of Labour and Employment (MTE) was choosen as it met all required prerequisites to develop the system and would provide, in addition, the number of employees of each establishment.

It is important to point out that the statement of RAIS is compulsory to all formal establishments in Brazil and receives information from over 5 million establishments, from all sectors of commerce, industry and services each and every fiscal year.

INMETRO receives data from RAIS without charge due to a cooperation agreement with MTE.

Step 2 - Selecting economic activities of interest: This was the hardest step for the development of SIMCS and was carried out by professionals with experience in verification of measuring instruments.

Using the National Classification of Economic Activities - CNAE 2.0 - these experts identified relevant economic activities associated with the use of measuring instruments regulated by INMETRO $[9,10]$. The emphasis of selection was directed to activities of the retail and wholesale trade, industry and service providers, including the ones in the health area.

SIMCS groups economic activities of interest to RBMLQ, that were selected from 1301 economic activities listed in CNAE 2.0. These groups of economic activities SIMCS enable tracking retail establishments, wholesalers, service providers and manufacturers that potentially use scales, fuel metering pumps, sphygmomanometers, among other instruments.

For example, the group of retail trade establishments that potentially utilize balances of classes III and IV small (up to $350 \mathrm{~kg}$ ) grouped the CNAE codes related to supermarkets, convenience stores, grocery stores, bakeries, butchers, home centers, liquefied petroleum gas, among others.

Another example refers to services in health area that potentially use sphygmomanometers and medical scales, and that included the CNAE codes related to hospitals, clinics, doctors, pharmacies, among others. 


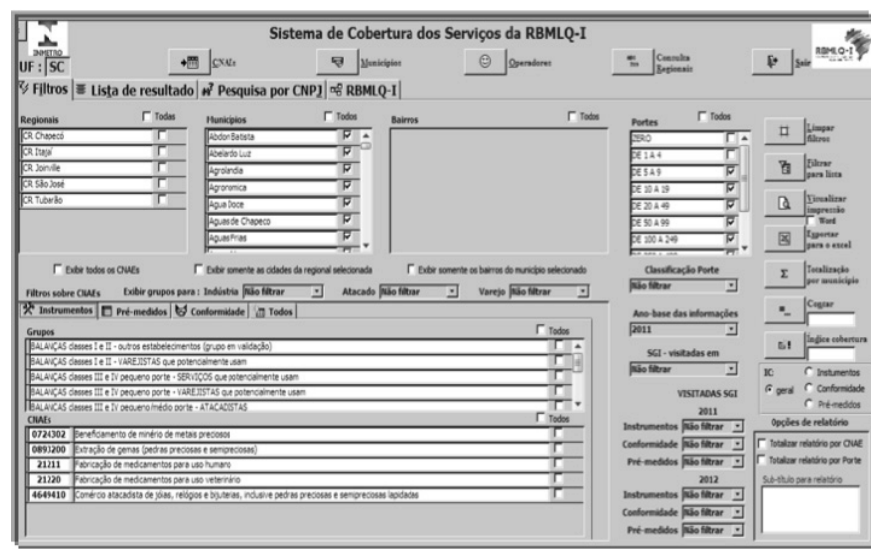

Fig. 2. SIMCS - main screen.

Step 3-Developing the computer architecture of SIMCS: SIMCS was developed by experts in databases and information technology, using the Microsoft Office Access platform.

This system required an organized storage of information for over 5 million establishments annually received from RAIS/MTE database and also from the Integrated Management System - SGI, Enterprise Resource Planning system used by RBMLQ, which stores data from more than 1140000 establishments visited during mandatory metrological verification of measuring instruments.

The development of SIMCS also considered the possibility of conducting queries using various filters such as: location (state, county, district), economic activity, size of the establishment based on the number of employees, among many others (Fig. 2).

These three steps of the construction endowed SIMCS with information and filters that enables to provide three major outputs of value to INMETRO and RBMLQ, as shown in Figure 3.

1st output: Estimation of the number of establishments subject to legal metrological control in the country. SIMCS can provide the total quantities of establishments that operate in activities that potentially use some type of measuring instrument regulated by INMETRO and, therefore, are subject to the mandatory periodic verification.

2nd output: When data from RAIS/MTE is compared with data from SGI, SIMCS calculates the Coverage Ratio (IC) of metrological verification of RBMLQ in Brazil, in any of its states and 5570 municipalities in its various areas of operation [6]. The IC is a percentage calculated by the following formula:

$$
\begin{aligned}
I C= & \frac{\text { no. of establishments actually visited by RBMLQ }}{\text { no. of establishments subject to the visit of RBMLQ }} \\
& \times 100 .
\end{aligned}
$$

The calculation of the IC reveals the non-registered establishments in SGI that, potentially, make use of measuring instruments.

3rd output: SIMCS provides detailed information about each of the establishments that are potential customers of RBMLQ, for example: their economic activity,

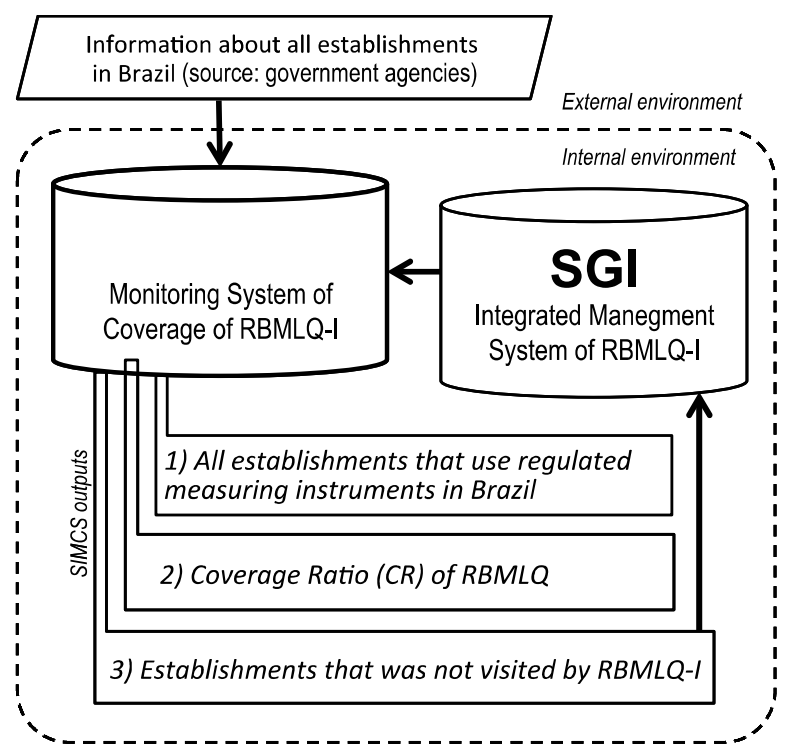

Fig. 3. Information flow - inputs and outputs.

size and full address. This facilitates the field visits to establishments that have not been visited and contributes to the expansion of coverage of mandatory periodic verification of measuring instruments [7].

Currently, with contributions from its users, SIMCS is being improved by specialists that work within a research project called PRONAMETRO, sponsored by INMETRO. New filters and database refining are under development.

The next section presents real examples of information provided by SIMCS, and shows how the system allows the user to perform queries and combine different information.

\section{Results and discussions}

The first feature of SIMCS is its capability to estimate the universe of establishments that operate in any economic activity subject to metrological control.

Table 1 presents the results of queries to estimate the number of establishments actually operating in relevant economic areas in Brazil. These queries used the following examples and combinations of filters:

(a) types of instruments to be searched: non automatic weighing instruments (NAWI), fuel dispensers and sphygmomanometers;

(b) types of activity: retail and service providers;

(c) geographic location at the country (Brazil), state (e.g. Rio Grande do Sul) and municipality (e.g. Cachoeira do Sul);

(d) size: only establishments with one (01) or more registered employees were selected.

The SIMCS query results with the number of establishments subject to legal metrological control in Brazil is an important reference for the management body of INMETRO and RBMLQ to estimate the size of the market in which they operate.

This information enables each delegated public body of RBMLQ to set their capacity to the existing demand 
Table 1. Estimation of the number of establishments actually operating in some economic areas in Brazil.

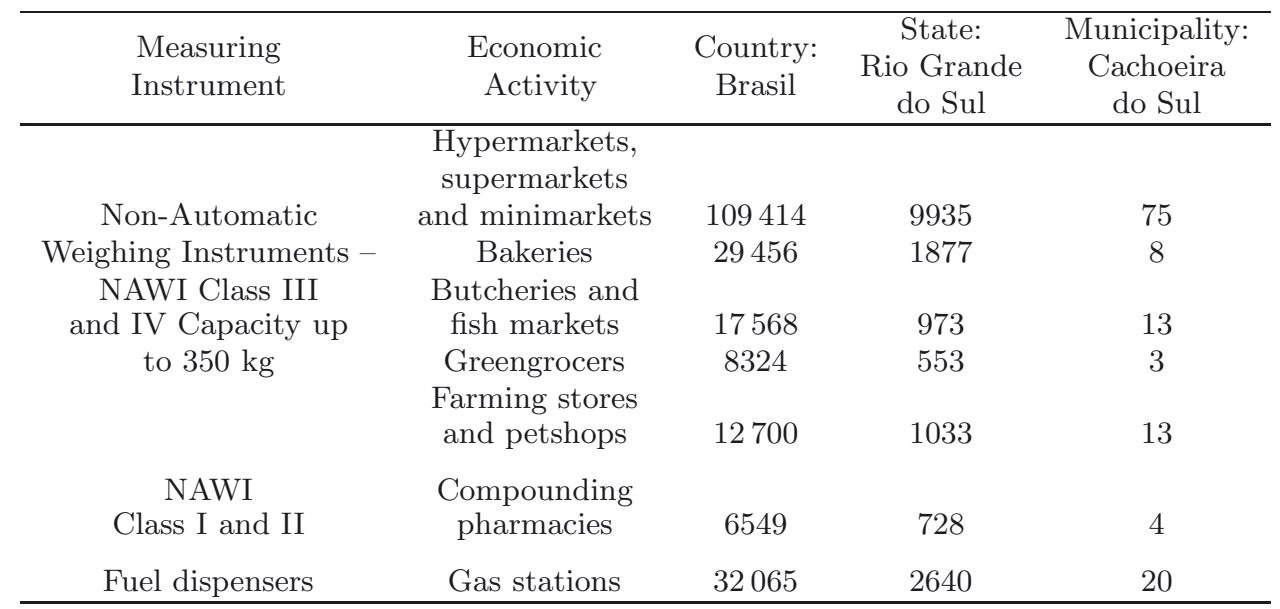

Table 2. CR of mandatory periodic verification in establishments in sectors of interest of RBMLQ in 2013.

\begin{tabular}{|c|c|c|c|}
\hline $\begin{array}{l}\text { Measuring } \\
\text { Instrument }\end{array}$ & $\begin{array}{c}\text { Economic } \\
\text { Activity }\end{array}$ & $\begin{array}{c}\text { CR Brasil } \\
(\%)\end{array}$ & $\begin{array}{c}\text { Highest } \\
\text { CR }(\%)-\text { State }\end{array}$ \\
\hline Non-Automatic & $\begin{array}{c}\text { Hypermarkets, } \\
\text { supermarkets and }\end{array}$ & & \\
\hline Weighing Instruments - & minimarkets & 66.8 & 79.6 - Tocantins \\
\hline NAWI Class & Bakeries & 67.9 & 78.3 - Paraná \\
\hline III and IV & Butcheries and fish markets & 67.7 & 80.9 - Paraná \\
\hline \multirow{2}{*}{ Capacity up to $350 \mathrm{~kg}$} & Greengrocers & 48.9 & 68.4 - Tocantins \\
\hline & Farming stores and petshops & 44.1 & 60.0 - Piauí \\
\hline $\begin{array}{c}\text { NAWI } \\
\text { Class I and II }\end{array}$ & Compounding pharmacies & 56.6 & 80.4 - Rio Grande do Sul \\
\hline Fuel dispensers & Gas stations & 88.6 & 93.5 - Espírito Santo \\
\hline
\end{tabular}

for their services, which may include hiring, relocation and training of personnel in areas where demand is higher than the current capacity.

Another important result is the automatic calculation of the Coverage Ratio (IC), which can be done in any geographic area and in any economic activity.

Table 2 compares the coverage achieved by RBMLQ for the entire country (IC Brazil) with the states that presentes the highest coverage in the country in 2012, in each of the selected economic activities.

The combination of query filters for measuring instruments and economic activities was similar to that used in Table 1.

The results presented in Table 2 indicates several growth opportunities, in different areas. The states with the highest IC of the country in 2012 showed that it is feasible to extend the coverage of mandatory periodic verification in all sectors surveyed. The state of Rio Grande do Sul, for example, reached coverage of $80.4 \%$ in pharmacies, while the average coverage in Brazil was only $56.6 \%$ in this same area.

It is also very much important to remind that SIMCS also provides a list with address and other relevant information that helps the identification of establishments that potentially make use of regulated measuring instruments and were not visited by RBMLQ. Such fact allows greater expansion of coverage and contributes to efficiency and effectiveness, thus reducing costs as far as the search for new establishments and those that have not been visted are concerned.

On the other hand, it is worth mentioning limitations. RAIS contains some inconsistencies regarding to economic activity of some establishments and that the percentage of establishments that are not active or that have changed their address increases as the data of this base becomes obsolete. Such matters make it unlikely that the coverage ratio can reach $100 \%[3,7]$.

\section{Conclusion}

The results shows that SIMCS can be a very important tool, for increasing the percentage of establishments undergoing on mandatory periodic verification of regulated measuring instruments in Brazil.

The calculation of the Coverage Ratio, provides strategic information for INMETRO and RBMLQ and also enables the following:

(a) monitoring the extent of mandatory periodic verification of measuring instruments in Brazil;

(b) revealing geographic areas and economic sectors not properly covered by metrological verification;

(c) planning of personnel and equipment needed to balance capacity and demand; 
(d) defining metrics;

(e) setting of realistic goals;

(f) comparing performance among the delegated institutes.

By estimating the universe of establishments targeted by INMETRO and RBMLQ in various sectors of industry, commerce and services in Brazil, SIMCS provides essential information for studies of impact analysis and risk regulations.

SIMCS also supports the juridical departments of RBMLQ, by confirming the addresses of the establishments as well as defining the size of the business which is determining as far as penalty amounts are concerned.

Currently, with contributions from its users, SIMCS is being improved by specialists that work within a research project called PRONAMETRO, sponsored by INMETRO. New filters and database refining are under development.

Finally, it is important to mention that the high number of establishments subject to legal metrological control in Brazil revealed by SIMCS implies a great challenge for RBMLQ. In principle, results indicate the need for a significant increase of personnel and equipment. On the other hand, results also indicate the need of further research in order to explore alternative models that shall be able to expand the metrological control of measuring instruments in Brazil with no big increase of government structures and expenses.

Acknowledgements. INMETRO, IMETRO/SC (delegated public institute in the state of Santa Catarina), PRONAMETRO and Mr Raimisson Costa (Researcher of INMETRO).

\section{References}

1. J. Birch, Benefit of legal metrology for the economy and society, Report - A study for the International Committee of Legal Metrology, 2003, p. 83

2. R. Sanders, Why do we regulate measuring instruments used for trade, OIML Bulletin LII, 13-15 (2011)

3. A.N. Soratto, O. Pohlmann Filho, M.R. Paiva, Sistemática para ampliação da cobertura da verificação metrológica legal no Brasil, in 6o Congresso Brasileiro de Metrologia (Anais. Rio Grande do Norte, 2011)

4. J.A.H Jornada, Melhoria Contínua e Transparência, Na Medida, Jornal Interno do INMETRO e da RBMLQ-I. Ano 25, 2 (2010)

5. P.R.M. Motta, Estado da arte da gestão pública, Rev. Adm. Empres. 53, 1 (2013)

6. L.A. Caldas, A.N. Soratto, O. Pohlmann Filho, Monitoramento na Rede Brasileira de Metrologia Legal e Qualidade do INMETRO, in Seminário da Rede Brasileira de Monitoramento e Avaliação (Anais. Ceará, 2010)

7. M.R. Paiva, O. Pohlmann Filho, A.N. Soratto, Prospecção do controle metrológico em balanças médicas e esfigmomanômetros em Santa Catarina, $7^{\circ}$ Congresso Brasileiro de Metrologia (Ouro Preto, 2013)

8. B. Amado Filho, A.N. Soratto, Metrologia legal no Brasil e consolidação da RBMLQ-I como modelo para o controle metrológico legal, $7^{\circ}$ Congresso Brasileiro de Metrologia (Ouro Preto/MG, 2013)

9. IBGE, CNAE 2.0, Classificação nacional de atividade econômica. Disponível em: http://www.ibge.gov.br/ concla/

10. IBGE, Estrutura detalhada da CNAE 2.0: seções, divisões, grupos e classes. Disponível em: http://www.ibge.gov. $\mathrm{br} /$ concla 